\title{
Functionalization of Single- and Multi-Walled Carbon Nanotubes with Cationic Amphiphiles for Plasmid DNA Complexation and Transfection
}

\author{
Cyrille Richard $(\varangle)$, Nathalie Mignet, Céline Largeau, Virginie Escriou, Michel Bessodes, and Daniel Scherman \\ ${ }^{1}$ Unité de Pharmacologie Chimique et Génétique,CNRS, UMR 8151, Paris, F-75270 cedex France \\ ${ }^{2}$ INSERM, U 640, Paris, F-75270 cedex France \\ ${ }^{3}$ Université Paris Descartes, Faculté des Sciences Pharmaceutiques et Biologiques, Paris, F-75270 cedex France \\ ${ }^{4}$ ENSCP, Paris, F-75231 cedex France \\ Received: 24 March 2009 / Revised: 27 May 2009 / Accepted: 27 May 2009 \\ CTsinghua University Press and Springer-Verlag 2009. This article is published with open access at Springerlink.com
}

\begin{abstract}
The possibility of delivering DNA efficiently to cells represents a crucial issue for the treatment of both genetic and acquired diseases. However, even although the efficiency of non-viral transfection systems has improved in the last decade, none have yet proven to be sufficiently effective in vivo. We report herein our results on the functionalization of single-walled carbon nanotubes (SWNT) and multi-walled carbon nanotubes (MWNT) by two cationic amphiphiles (lipid RPR120535 and pyrenyl polyamine), their use for the complexation of plasmid DNA, and their efficiency in transfecting cells in vitro. The experiments have shown that the efficiency of transfection is higher when using SWNT instead of MWNT, and that transfection efficiency is similar or slightly higher when using nanoplexes (SWNT/lipid RPR120535/DNA) instead of lipoplexes (lipid RPR120535/DNA) and several orders of magnitude higher than that of naked DNA. This study therefore shows both that the transfection is better when using SWNTs and that it is dependent on the nature of the amphiphilic molecules adsorbed on the nanotubes.
\end{abstract}

\section{KEYWORDS}

Carbon nanotubes, amphiphile, gene delivery, plasmid DNA, in vitro

\section{Introduction}

The possibility of delivering DNA efficiently to cells represents a crucial issue for the treatment of both genetic and acquired diseases. In order to improve gene delivery into cells both in vitro and in vivo, increasing attention has been focused on the development of methods and vectors capable of efficiently delivering DNA to the target cells. A large array of non-viral transfection agents are used for in vitro applications. These include cationic peptides, dendrimers, polycationic polymers and, probably the most popular, cationic lipids [1-6]. The efficiency of non-viral transfection systems has improved in the last decade. However, none have yet proven to be sufficiently effective in vivo, and new developments

Address correspondence to cyrille.richard@parisdescartes.fr 
are still on-going.

Recently, carbon nanotubes (CNTs) [7], a novel well-studied nanomaterial composed only of carbon atoms, have been investigated for their ability to interact with biological materials. For instance, CNTs have been found to enhance DNA amplification in polymerase chain reactions (PCR) [8], affect the growth pattern of neurons [9] and deliver peptides, genes or proteins into cells via the endocytic pathway [10-16]. CNTs are formed by rolling sheets of graphite-like carbon (a flat network of fused benzene rings with $\mathrm{sp}^{2}$ hybridization) to create hollow tubes [7]. They are classified based on the number of carbon layers assembled together, as single-walled nanotubes (SWNTs) or multi-walled nanotubes (MWNTs). Their diameter varies according to the number of layers: $0.4-2 \mathrm{~nm}$ for SWNTs and from 2-100 $\mathrm{nm}$ for MWNTs. The length of the tubes is dependent on the method of production, and can vary from $500 \mathrm{~nm}$ to tens of micrometers. The exceptional mechanical and electronical properties of these materials make them good candidates for applications in material science and electronics [17]. However, one obstacle to the use of CNTs is their insolubility in most solvents. Methods have been reported to covalently functionalize the outer surface of CNTs [18]. Recently, we have reported a simple method to noncovalently functionalize the surface of CNTs with amphiphilic molecules [19, 20]. The amphiphile adsorbed on the CNTs creates charges on the surface, thus preventing aggregation in biological media. One of the research topics of our laboratory relates to the use of cationic amphiphiles able to interact with plasmid DNA for gene delivery [21]. Could cationic amphiphiles adsorbed on the surface of CNT complex plasmid DNA and increase the efficiency of cell transfection compared to plasmid DNA complexed with the cationic amphiphiles alone? To answer this question, we report herein our results on the synthesis of two amphiphilic molecules able to functionalize the outer surface of SWNTs and MWNTs, their use for the complexation of plasmid DNA, and their efficiency in transfecting cells in vitro (Scheme 1). In parallel, the same amphiphilic molecules when not adsorbed on the surface of CNTs, were incubated with plasmid DNA and also used to transfect the same cells. To the best of our knowledge, this is the first time such a comparative study has been reported.

\section{Materials and methods}

All solvents were purchased from Carlo Erba-SDS. All chemicals were purchased from Sigma-Aldrich-Fluka or Lancaster. SWNTs $(0.5-2 \mu \mathrm{m}$ in length, $1-2 \mathrm{~nm}$ in diameter) and MWNTs (0.5-2 $\mu \mathrm{m}$ in length, 20-30 nm in diameter) were purchased from Aldrich. Reactions were monitored by thin layer chromatography using Merck precoated 60 F254 silica gel plates. Column chromatography was performed with SDS 35-70 $\mu \mathrm{m}$ silica gel. ${ }^{1} \mathrm{H}$ and ${ }^{13} \mathrm{C}$ nuclear magnetic resonance (NMR) spectra were recorded on a Bruker Avance DRX-300 spectrometer at $400 \mathrm{MHz}$ for ${ }^{1} \mathrm{H}$ and 100 $\mathrm{MHz}$ for ${ }^{13} \mathrm{C}$.

\subsection{Synthetic procedures}

Synthesis of protected pyrenyl polyamine 3. A solution of 1-pyrenebutyric acid $\mathrm{N}$-hydroxysuccinimide ester $\mathbf{1}(100 \mathrm{mg}, 250 \mu \mathrm{mol})$ in dimethylformamide (DMF) (5 $\mathrm{mL}$ ) was slowly added to a solution of the protected amine 2 [22] (500 mg, $1.2 \mathrm{mmol})$ in DMF (10 mL)

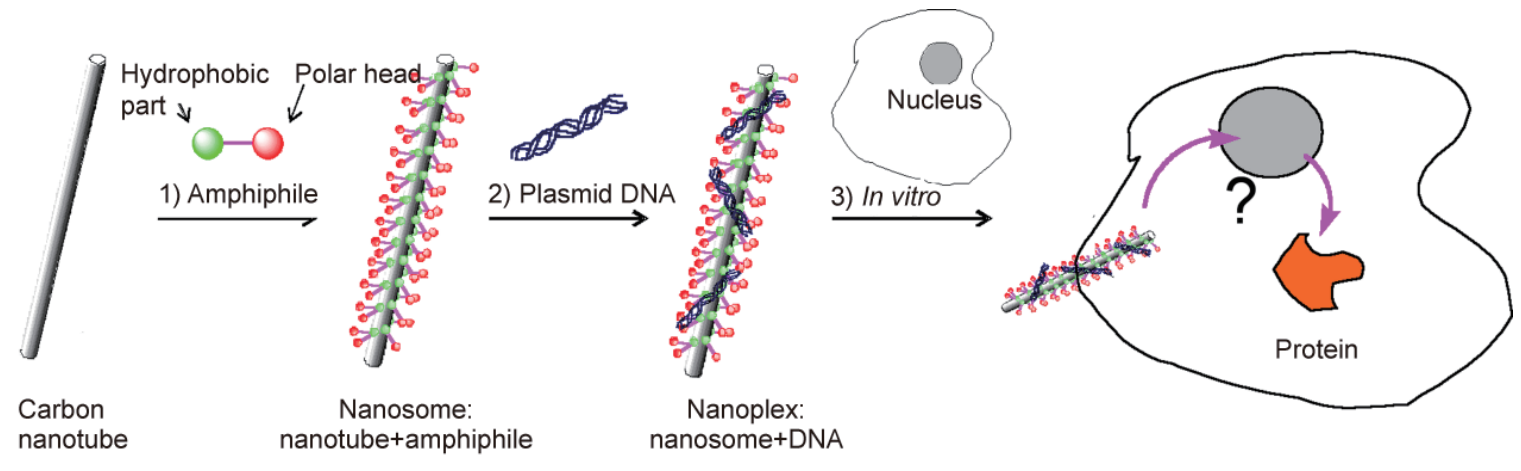

Scheme 1 Principle of functionalization of CNTs by amphiphiles and their use for plasmid DNA transfection 
and triethylamine (TEA) $(335 \mu \mathrm{L}, 2.4 \mathrm{mmol})$. The reaction mixture was stirred for $12 \mathrm{~h}$, evaporated to dryness and chromatographed on silica gel $\left(\mathrm{CH}_{2} \mathrm{Cl}_{2} /\right.$ methanol: 9/1) to yield $100 \mathrm{mg}$ of compound $3(60 \%)$. ${ }^{1} \mathrm{H}$ NMR $\left(\mathrm{CDCl}_{3}\right) \delta: 1.43-1.52(m, 22 \mathrm{H}) ; 2.2-2.4(m$, $10 \mathrm{H})$; 3.20-3.40 (m, 12H); 6.70-6.85 (br s, 1H); 8.3$7.8(m, 9 \mathrm{H}) .{ }^{13} \mathrm{C} \mathrm{NMR}, \mathrm{CDCl}_{3}, \delta: 27.2,27.7,28.4,28.8$, 29.0, 35.4, 35.9, 37.4, 37.7, 43.1, 43.3, 43.8, 44.2, 46.2, 46.7, 79.0, 79.6, 79.6, 79.8, 123.3, 124.9, 125.0, 126.2, 126.6, 127.4, 127.5, 128.1, 129.5, 130.4, 130.9, 135.6, 155.5, 156.1, 156.5, 173.5 .

Synthesis of pyrenyl polyamine 4. Compound 3 (50 mg, $75 \mu \mathrm{mol}$ ) was dissolved in $\mathrm{CH}_{2} \mathrm{Cl}_{2}(5 \mathrm{~mL})$ and cooled to $0{ }^{\circ} \mathrm{C}$. Trifluoroacetic acid (TFA) $(250 \mu \mathrm{L}, 3$ $\mathrm{mmol}$ ) was added, the mixture was allowed to warm to room temperature (RT) and stirred for $12 \mathrm{~h}$, and then evaporated to dryness to yield compound 4 (30 $\mathrm{mg}, 90 \%) .{ }^{1} \mathrm{H}$ NMR $\left(\mathrm{D}_{2} \mathrm{O}\right) \quad \delta: 1.70-1.84(m, 4 \mathrm{H}), 1.84-$ $1.95(m, 2 \mathrm{H}), 2.09(q, 2 \mathrm{H}, J=8 \mathrm{~Hz}), 2.2-2.4(m, 6 \mathrm{H}), 2.95$ $-3.19(m, 10 \mathrm{H}), 3.19-3.30(m, 2 \mathrm{H}), 8.3-7.8(m, 9 \mathrm{H}) .{ }^{13} \mathrm{C}$ NMR, $\mathrm{D}_{2} \mathrm{O}, \delta: 36.8,37.3,45.4,46.0,47.8,123.3,124.9$, 125.0, 126.2, 126.6, 127.4, 127.5, 128.1, 129.5, 130.4, $130.9,135.6,155.5,177.2$.

The lipid RPR120535 was prepared as described earlier [22].

\subsection{Physicochemistry and biology}

Preparation of nanosomes. Nanosomes (corresponding to the association of CNTs and the amphiphile) were prepared as follows: One milligram of CNTs (either SWNT or MWNT) was mixed with $100 \mu \mathrm{L}$ of the cationic amphiphile (either the pyrenyl polyamine 4 or lipid RPR120535) at a concentration of $1 \mathrm{mg} / \mathrm{mL}$, diluted in $900 \mu \mathrm{L}$ of milliQ water and sonicated for 5 min.

Preparation of nanoplexes. Nanoplexes (corresponding to the association of nanosomes and plasmid DNA) were prepared in water with different charge ratios (CR), which correspond to the number of moles of amine divided by the number of moles of phosphate. The plasmid DNA contained the luciferase reporter gene under the cytomegalovirus (CMV) promoter. After purification, the plasmid was mainly obtained as the super coiled (SC) form with a very low percentage of open circular (OC) form. To prepare $200 \mu \mathrm{L}$ of nanoplexes at $\mathrm{CR}=2,50 \mu \mathrm{L}$ of DNA
$(0.016 \mu \mathrm{g} / \mu \mathrm{L})$ were added to $160 \mu \mathrm{L}$ of nanosomes. Complexes were allowed to form for $30 \mathrm{~min}$ at room temperature prior to use. This process was repeated for each CR tested.

Scanning electron microscopy (SEM). SEM was used to image MWNT and SWNT functionalized by lipid RPR120535 and incubated with DNA. Imaging was carried out by placing a $30 \mu \mathrm{L}$ drop of nanoplexes with $\mathrm{CR}=4$, allowed to dry and coated with gold. Imaging was carried out with a Philips XL 30 scanning electron microscope. Images were captured and saved digitally.

Gel retardation experiments. DNA $(0.3 \mu \mathrm{g})$ complexed to the different types of nanosomes at different CRs, and DNA (0.3 $\mu \mathrm{g})$ as a control, was loaded on a $0.8 \%$ agarose gel in TBE buffer $(1 / \mathrm{L}$ Tris, $0.9 \mathrm{~mol} / \mathrm{L}$ boric acid, $0.01 \mathrm{~mol} / \mathrm{L}$ ethylenediaminetetraa cetic acid (EDTA) at $80 \mathrm{~V} / \mathrm{cm}$. DNA was revealed with ethidium bromide and visualized under UV light.

Light scattering experiments. Dynamic light scattering (DLS) was used to detect cationic lipoplexes in the supernatant of nanoplexes. For this purpose, nanoplexes were prepared at $\mathrm{CR}=2$ as described above. Since this ratio leads to aggregation of the nanoplexes, the supernatant was recovered and analyzed. The scattering intensity was measured for this supernatant using a Zetasizer Malvern Nano Series equipped with a He-Ne laser $(\lambda=633 \mathrm{~nm}$, $4.0 \mathrm{~mW}$ ) and backscattering detection (scattering angle of $173^{\circ}$ relative to the laser source). In parallel, the same experiment was done with a sample of lipoplexes (lipid cationic/DNA) at the same CR. For measurement, $5 \mu \mathrm{L}$ of complexes were diluted in 900 $\mu \mathrm{L}$ of milliQ water.

Cell culture. B16 murine melanoma cells were grown in Dulbecco's Modified Eagle's Medium (Dulbecco's modified Eagle's medium (DMEM), Gibco) supplemented with $10 \%$ (v/v) fetal bovine serum (FBS), L-glutamine $(2 \mathrm{mmol} / \mathrm{L})$, penicillin (50 U/mL), streptomycin $(50 \mathrm{U} / \mathrm{mL})$. Cultures were maintained at $37^{\circ} \mathrm{C}$ in a $5 \% \mathrm{CO}_{2} /$ air incubator.

Internalization experiments. The day before the experiment, B16 cells were seeded into 12-well culture plates containing lamella at a density of 80,000 cells per well. Wells were washed and DMEM was added. The nanoplexes $(0.5 \mu \mathrm{g}$ of luciferase 
plasmid/well) were added to the cells. Then, $10 \%(\mathrm{v} / \mathrm{v})$ FBS was added to the culture wells containing serum-free lipofectin medium after $2 \mathrm{~h}$ at $37^{\circ} \mathrm{C}$. The

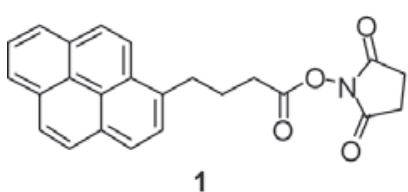

1

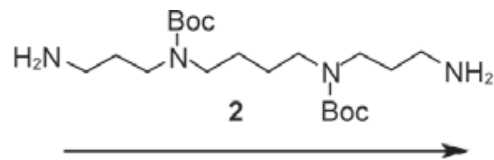

DMF, TEA cells were incubated in the darkness for $24 \mathrm{~h}$ at $37^{\circ} \mathrm{C}$ in the presence of $5 \% \mathrm{CO}_{2}$. Cells were washed with $500 \mu \mathrm{L}$ phosphate buffered saline (PBS) and then fixed with paraformaldehyde (500 $\mu \mathrm{L} \mathrm{3 \%}$ in PBS). After $30 \mathrm{~min}$ incubation in the dark, cells were washed with $500 \mu \mathrm{L}$ PBS and mounted in polyvinyl alcohol (Mowiol) prior to examination. Slides were then analyzed with a Zeiss Axiophot microscope equipped with a Zeiss Neofluar $100 \times$ objective lens.

Transfection. One day before transfection, B16 murine melanoma cells were seeded into 24 well plates $(45,000$ cells / well) and incubated $24 \mathrm{~h}$ at $37^{\circ} \mathrm{C}$. A

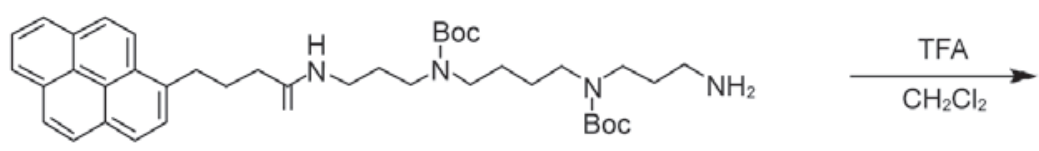
3

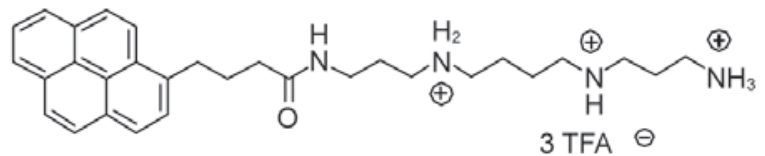

Pyrenyl polyamin 4

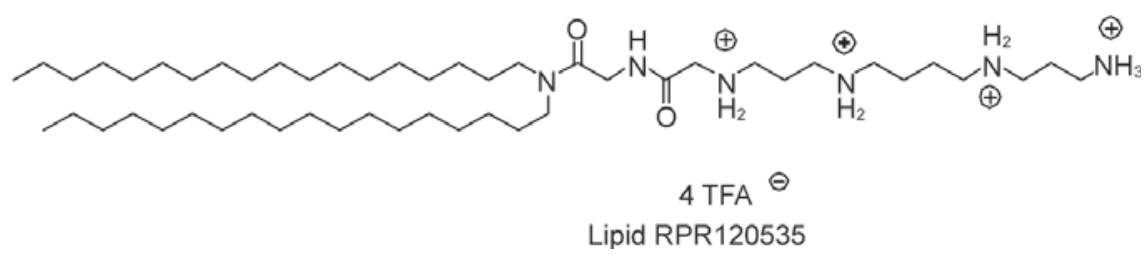

Scheme 2 Synthesis of pyrenyl polyamine $\mathbf{4}$ and structure of lipid RPR120535 volume of $100 \mu \mathrm{L}$ of nanoplexes

(CNT/ cationic amphiphile/DNA) (corresponding to $0.5 \mu \mathrm{g}$ DNA) was loaded on each well, and the plates were incubated at $37^{\circ} \mathrm{C}$ for $48 \mathrm{~h}$. Then, the cells were washed twice with PBS and treated with $200 \mu \mathrm{L}$ of a passive lysis buffer (Promega). After $15 \mathrm{~min}$, the cell lysates were centrifuged for $5 \mathrm{~min}$ at 12,000 rpm. The supernatant $(10 \mu \mathrm{L})$ and $10 \mu \mathrm{L}$ of iodoacetamide were deposited on a 96 well plate, which was incubated at $37^{\circ} \mathrm{C}$ for $1 \mathrm{~h}$. Protein quantification was performed with the bicinchoninic acid (BCA) Protein Assay Kit (Pierce) and reported relative to BCA taken as a reference curve. Luciferase activity was quantified using a commercial kit Luciferase Assay System (Promega). To $10 \mu \mathrm{L}$ of the lysed cells, $50 \mu \mathrm{L}$ of the luciferin substrate was injected via an injector, and the luminescence was read immediately on a luminometer (Multilabel counter 1420 Victor2 Wallac). Counts per second (CPS) were calculated versus background activity. Light emission was normalized to the protein concentration of cell extracts, determined as described above.

\section{Results and discussion}

\subsection{Chemistry}

The pyrenyl polyamine 4 was prepared in two steps from commercially available 1-pyrenebutyric acid $N$-hydroxysuccinimide ester. The first step is a reaction with protected amine 2 , followed by a deprotection step with TFA (Scheme 2). Compound 4 was prepared with an overall yield of $55 \%$.

\subsection{Functionalization}

Pyrenyl polyamine 4 and lipid RPR120535 were used to functionalize the outer surface of CNTs (SWNT or MWNT, step 1 in Scheme 1). Several assays were realized to find the quantity of amphiphile necessary to allow a good functionalization of the surface of the CNTs. When $1 \mathrm{mg}$ of CNT (MWNT or SWNT) was dispersed alone in water, aggregation of the CNT occured (Fig. 1(a)). However, when MWNT 
was mixed with $100 \mu \mathrm{L}$ of a solution of amphiphile (pyrenyl polyamine, Fig. 1(b) or lipid RPR120535, Fig. $1(\mathrm{c}))$ at a concentration of $1 \mathrm{mg} / \mathrm{mL}$ and diluted in $900 \mu \mathrm{L}$ of water, stable suspensions of the CNTs were obtained. Similar results were obtained when SWNT were mixed with pyrenyl polyamine 4 (Fig. 1(d)) and with lipid RPR120535 (Fig. 1(e)).

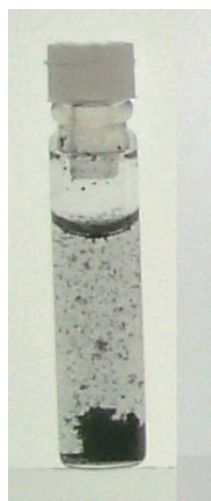

(a)

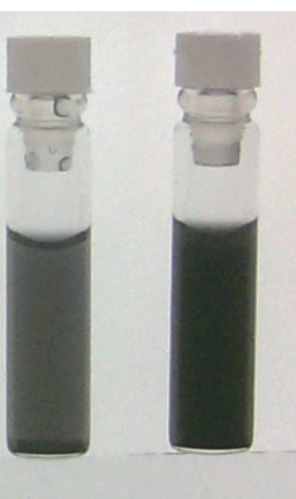

(b)

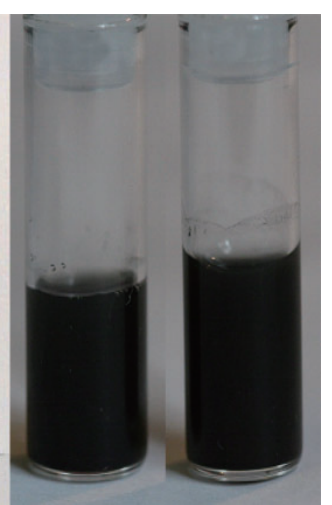

(d) (e)
Figure 1 Functionalization of CNT with two different amphiphiles. (a) SWNT (or MWNT) in water; (b) MWNT and pyrenyl polyamine 4; (c) MWNT and lipid RPR120535; (d) SWNT and lipid RPR120535; (e) SWNT and pyrenyl polyamine 4. CNT: $1 \mathrm{mg}$, concentration of amphiphile: $0.1 \mathrm{mg} / \mathrm{mL}$, observation: $10 \mathrm{~min}$ after sonication lipid RPR120535 at a CR below 1, DNA was not completely retained by the CNTs and could migrate on the gel (Fig. 2(a), MWNT/L, lanes 0.25 and 0.5). However, if the $\mathrm{CR}$ was higher than 1 , no migration of DNA occurred (Fig. 2(a), MWNT / L, lanes 1 and 2). Similar results were obtained when lipid RPR120535 was incubated with plasmid DNA. At a CR below 1 , plasmid was not completely retained on the gel (Fig. 2(a), L, lanes 0.25 and 0.5). However, when the CR was higher than 1, DNA was completely retained on the gel (Fig. 2(a), L, lanes 1 and 2). These results indicate that the adsorption of lipid on the surface of the CNTs before its incubation with DNA does not change its capacity to complex DNA.

Figure 2(b) shows the results obtained using MWNT and pyrenyl polyamine 4 . For a CR between 0.25 and 4, plasmid DNA was not retained by pyrenyl polyamine and could migrate on the gel (Fig. 2(b), 4, lanes 0.25 to 4 ). When the experiments were carried out in the presence of MWNT, the SC form of DNA was fully retained at a CR equal to 4 (Fig. 2(b), MWNT/4, lane 4). At CR equal to 1 or 2, the band intensity corresponding to the OC form tended to increase. This observation has already

\subsection{Complexation}

The nanosomes (MWNT or SWNT functionalized by the cationic molecules) were incubated with plasmid DNA (step 2 in Scheme 1) in water at different CRs. After incubation for $30 \mathrm{~min}$ at room temperature, $30 \mu \mathrm{L}$ of the nanoplexes (CNT/cationic molecules/DNA) were loaded on an agarose gel and electrophoresed.

Figure 2(a) shows the results obtained using MWNT and lipid RPR120535. When DNA was used alone, two bands are visible (OC and SC) and migrate on the gel as can be seen in lane A. When MWNT were incubated with plasmid DNA, but without the amphiphilic molecule, DNA was not adsorbed on the CNTs and migrated on the gel (lane B). When MWNTs were covered by

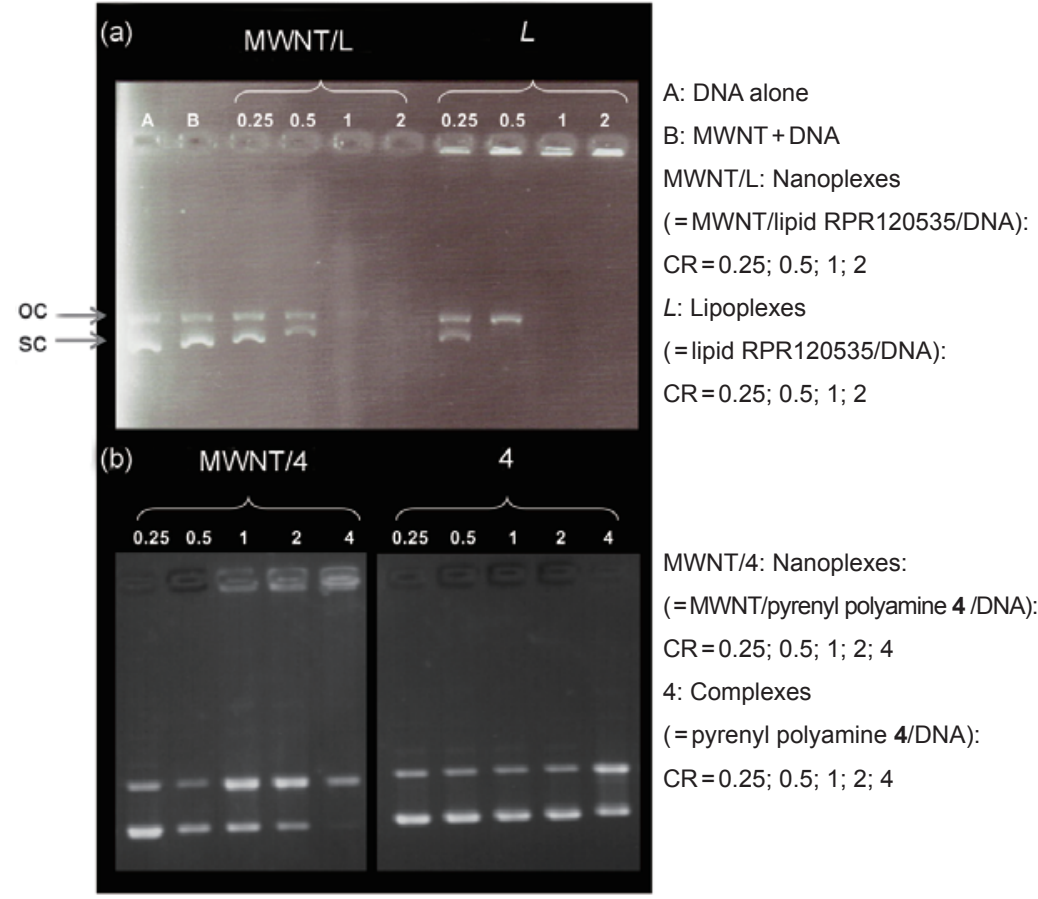

Figure 2 Gel retardation experiments at different CR. (a) MWNT, lipid RPR120535 and DNA; (b) MWNT, pyrenyl polyamine 4 and DNA. OC=open circular, SC = super coiled 
been previously reported for SWNT covalently functionalized by ammonium groups [16]. This suggests that the interaction of the CNTs with DNA might induce a conformational change, which might be avoided by a lipid layer on the top of the CNTs.

Similar experiments were realized with SWNT functionalized either by lipid RPR120535 or by pyrenyl polyamine 4 (Fig. 3). When the experiments were performed with SWNT functionalized by lipid RPR120535, plasmid DNA was retained on the gel for a CR higher than 0.5 (Fig. 3(a), SW/L, lanes 0.5 to 4). When the experiments were performed with SWNT functionalized by pyrenyl polyamine 4, the SC band of plasmid DNA was completely retained on the gel when the CR was equal to 1 (Fig. 3(b), SW/4, lane 1). However, at the same CR, plasmid DNA was not retained on the gel when using pyrenyl polyamine 4 alone (Fig. 3(b), 4, lane 1).

Addition of DNA to cationic amphiphiles adsorbed on the CNTs could possibly detach the cationic molecules from the surface of the CNTs. To see if the complexes formed between DNA and cationic lipids on the surface of the CNTs were stable, we used conditions leading to aggregation of the nanoplexes. After sedimentation of the nanoplexes, scattering intensity was measured in the supernatant. First of all, solutions of lipoplexes were observed by this technique and as shown in Fig. 4, as the quantity of lipoplexes (association of lipid RPR120535 and DNA) increased, the scattering intensity increased as well (blue line). When the same experiment was repeated with the supernatant of nanoplexes (SWNT + lipid RPR120535 incubated with DNA at $\mathrm{CR}=2$ ), some lipoplexes were detected in the solution (pink line), indicating that not all the complexes (lipid RPR120535/DNA) were adsorbed on the CNT. However, when the experiment was carried out with MWNT functionalized by lipid RPR120535 and incubated with DNA, no particles were detected in the supernatant (green line).

The same experiments were realized using pyrenyl polyamine 4, SWNT, MWNT, and DNA (Fig. 5). No particles were detected in the supernatant indicating that all of the amphiphile used was adsorbed on the surface of the CNTs (SWNT or MWNT) and that the association was stable. The nature of the hydrophobic

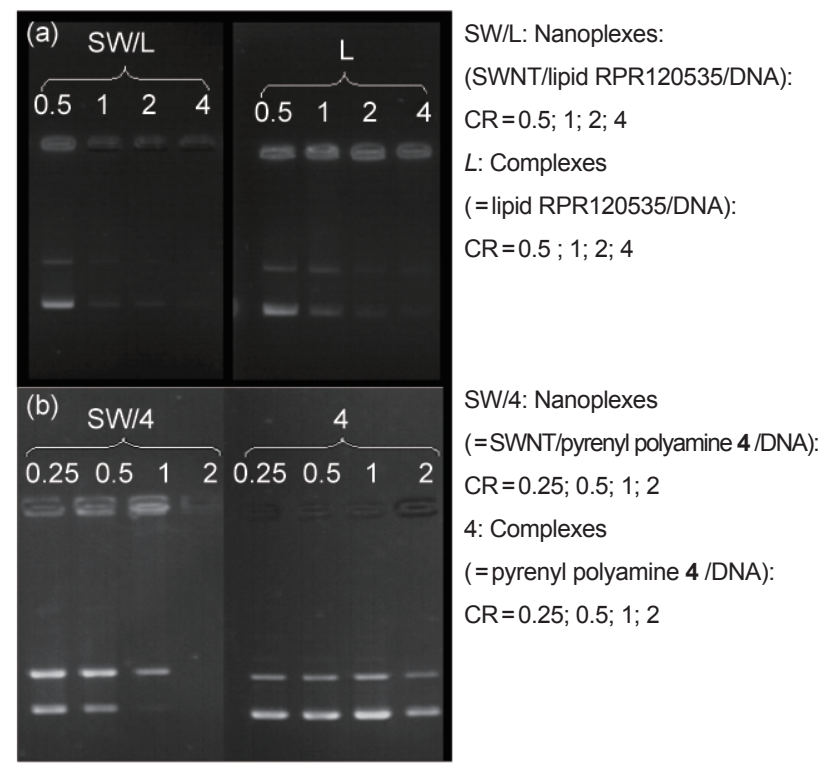

Figure 3 Gel retardation experiments at different charge ratio (CR): (a) SWNT, lipid RPR120535 and DNA; (b) SWNT, pyrenyl polyamine $\mathbf{4}$ and DNA

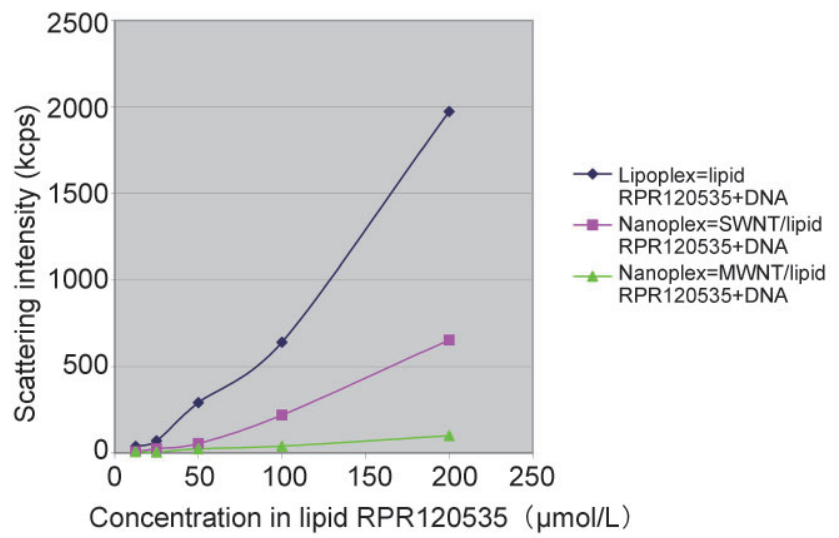

Figure 4 Light scattering intensity of the particles detected in the supernatant by dynamic light scattering using lipid RPR120535

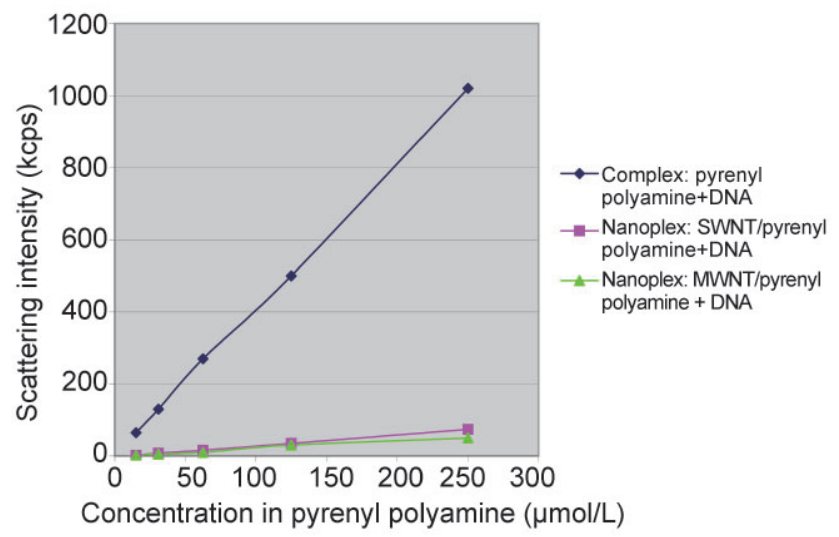

Figure 5 Light scattering intensity of the particles detected in the supernatant by dynamic light scattering using pyrenyl polyamine $\mathbf{4}$ 
part (the pyrenyl group in this case) could be responsible for a better interaction with the surface of the CNTs, leading to a higher stability of the complex formed at the CNT surface [20,23].

Then, MWNTs covered by lipid RPR120535 and incubated with plasmid DNA for 30 min were deposited on B16 cells and observed under an optical microscope. The nanoplexes either adsorbed or internalized into the cells are clearly visible in Fig. 6.

\subsection{Transfection}

Finally, we looked at the gene-transfer efficiency of the various CNT/amphiphilic molecules/DNA complexes prepared (step 3 in Scheme 1). To promote the interaction with the negatively charged cell membranes, the experiments were performed at CR from 4 to 10. The data demonstrate that all types of complexes are able to transfect B16 cells with better efficiency than naked DNA (Figs. 7-9). However, depending on the type of CNTs used (SWNT or MWNT) and the nature of the amphiphilic molecule adsorbed (pyrenyl polyamine 4 or lipid RPR120535), efficiencies of gene transfer vary.

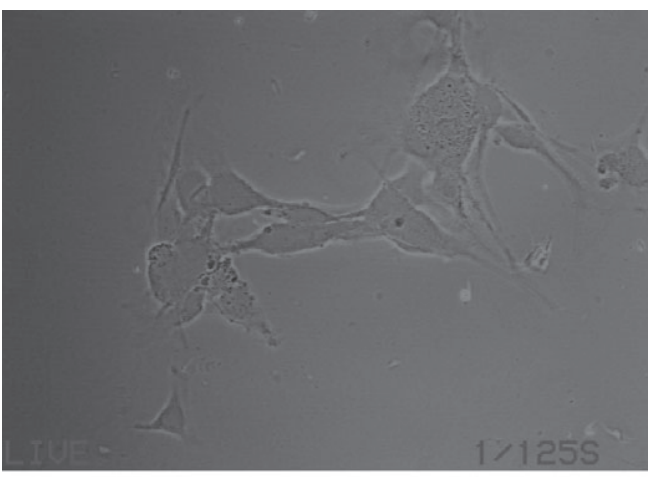

(a)

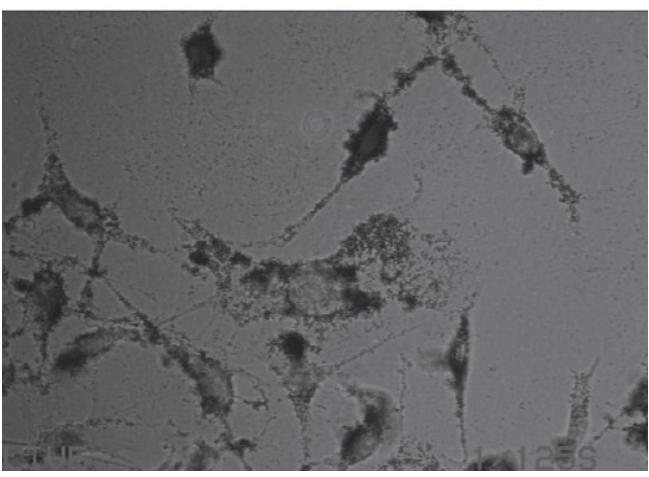

(b)

Figure 6 Observations with optical microscope: (a) B16 cells; (b) B16 cells incubated with nanoplexes

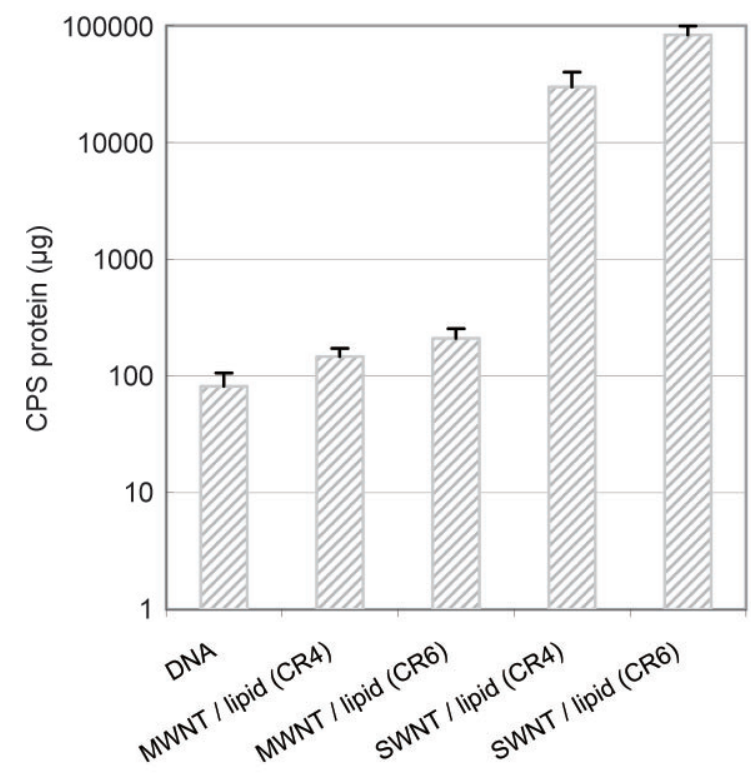

(a)

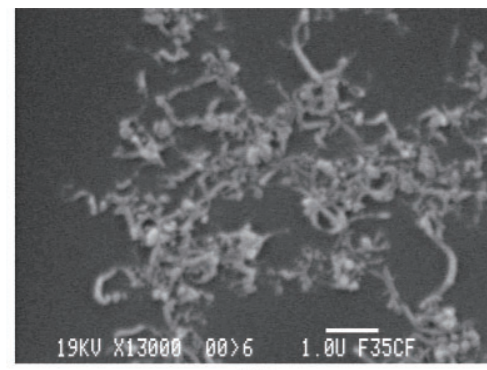

(b)

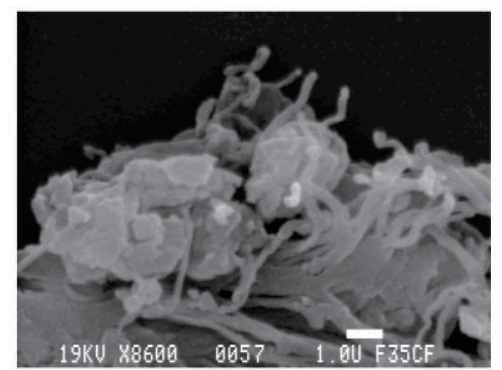

(c)

Figure 7 (a) Comparison of the efficiency of transfection using SWNT or MWNT functionalized by lipid RPR120535; (b) SEM of MWNT/lipid RPR120535/DNA at CR=4; (c) SEM of SWNT/lipidRPR 120535/DNA at CR=4, scale bar $1 \mu \mathrm{m}$ 


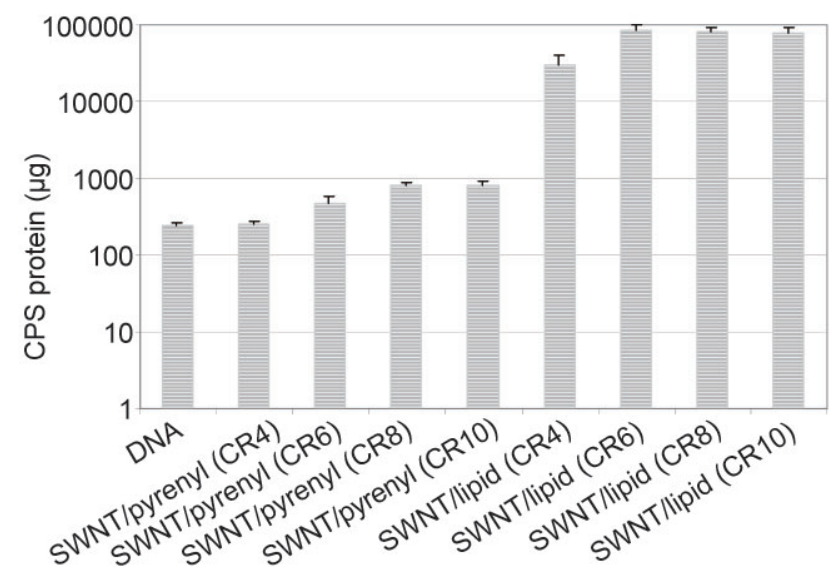

Figure 8 Comparison of the efficiency of transfection using SWNT functionalized either by pyrenyl polyamine $\mathbf{4}$ or by lipid RPR120535 with $C R=4-10$

First of all, we compared the efficiency of transfection using either SWNT or MWNT covered by the lipid RPR120535 at CR equal to 4 and 6 . As can be seen in Fig. 7(a), the efficiency of transfection of MWNT functionalized by the lipid is slightly higher than when using naked DNA, but is much less effective than when using SWNT functionalized by the same lipid. When we looked at the morphological characteristics of the resulting nanoplexes by SEM, we can see that they present different structural features, as shown in Figs. 7(b) and 7(c). We hypothesize that in the case of SWNT, the larger size complexes stable in the suspensions could be responsible for a better internalization into the cells which would increase the transfection efficiencies. The same observation has already been reported using lipoplexes where transfection efficiencies are better under conditions where aggregates are present [24].

We then compared the efficiency of transfection of SWNT functionalized either by the lipid RPR120535 or by the pyrenyl polyamine 4 . As can be seen in Fig. 8 , the adsorbed molecule plays a key role since the efficiency of transfection is 100 times higher when using the SWNT functionalized by the lipid instead of pyrenyl polyamine 4 . When we looked at the stability of the complexes we can see some differences. The complexes formed with pyrenyl polyamine $\mathbf{4}$ are not stable between CR 4 and 10 and quickly fall to the bottom of the tubes, unlike those formed with lipid

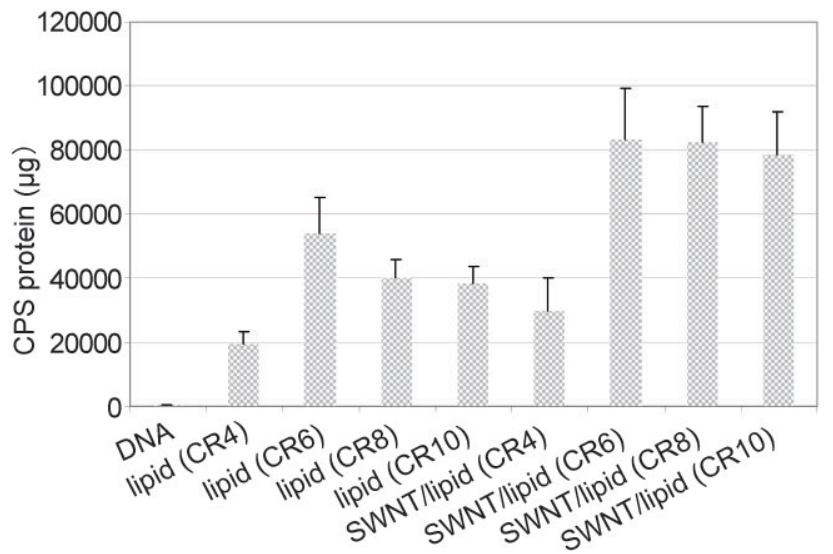

Figure 9 Comparison of the efficiency of transfection using lipid RPR120535 formulated with DNA or adsorbed on SWNT and incubated with DNA with $C R=4-10$

RPR120535 which remain stable. It is possible that the large size of the aggregates formed during the sedimentation could prevent a good internalization of the nanoplexes into the cells, explaining the lower transfection efficiencies. It should be noted that addition of DNA to the SWNT-pyrenyl polyamine 4 led to complex aggregation which did not occur for SWNT-lipid complexes. DNA might have been trapped in these aggregates which could explain the observed difference in transfection efficiency.

Finally, the efficiency of transfection using SWNT functionalized by lipid RPR120535 was compared to the efficiency of the lipoplex, i.e., lipid RPR120535 formulated with plasmid DNA not adsorbed on CNTs. As could be seen in Fig. 9, when the lipid is first adsorbed on SWNT, the efficiency is higher than when the lipid is used as lipoplexes. The presence of a small portion of free lipoplexes in the suspension can not be solely responsible for these results, thus demonstrating an effect of the SWNT, as already observed in earlier work [11, 13, 16].

When we compare the efficiency of transfection using these nanoplexes with the results obtained using DNA alone, our conditions lead to better results than those using CNT covalently functionalized by ammonium ions reported in Refs. $[10,11]$, probably because of a larger quantity of functional groups present on the surface of our CNTs. Moreover, our results are similar to those obtained with CNT functionalized by a cationic polymer, 
polyethyleneimine (PEI) [14].

However, one major disavantage of this type of compound is the possible equilibrium between free and adsorbed molecules. To avoid this phenomenon, another family of amphiphilic molecules, bearing a diacetylene group in the aliphatic chain could be prepared. Such molecules, once adsorbed on the surface of the CNTs could be irradiated with a UV lamp. This treatment would induce a polymerization of the amphiphile, stabilizing it on the surface of the CNTs, as already reported in Ref. [25]. This could be useful to remove the excess lipid not adsorbed on the surface of the CNTs without removing the lipid from the CNT surface.

\section{Conclusions}

Our objective was to evaluate the efficiency of transfection using either nanoplexes (SWNT or MWNT noncovalently functionalized by amphiphilic molecules and incubated with plasmid DNA) or lipoplexes (using the same amphiphilic molecules plus plasmid DNA). The experiments have shown that the diameter of the CNTs plays a key role in the transfection process since the efficiency of transfection was higher when using SWNT instead of MWNT, and that the transfection is dependent on the nature of the amphiphilic molecules adsorbed on the CNTs, since better results were obtained when using SWNT functionalized by lipid RPR120535 instead of pyrenyl polyamine B. Finally, transfection is similar or slightly higher when using nanoplexes (SWNT/ lipid RPR120535/DNA) instead of lipoplexes alone (lipid RPR120535/DNA).

\section{Acknowledgements}

The authors thank René Lai-Kuen (University Paris Descartes, Service Commun d'Imagerie Cellulaire et Moléculaire) for his help with SEM experiments.

\section{References}

[1] Zelphati, O.; Nguyen, C.; Ferrari, M.; Felgner, J.; Tsai, Y.; Felgner, P. L. Stable and monodisperse lipoplex formulations for gene delivery. Gene Ther. 1998, 5, 1272-1282.
[2] Boussif, O.; Lezoualc'h, F.; Zanta, M. A.; Mergny, M. D.; Scherman, D.; Demeneix, B.; Behr, J. P. A versatile ersatile vector for gene and oligonucleotide transfer into cells in culture and in-vivo-polyethylenimine. Proc. Natl. Acad. Sci. USA 1995, 92, 7297-7301.

[3] Haensler, J.; Szoka, F. C. Jr. Polyamidomine olyamidoamine cascade polymers mediate efficient transfection of cells in culture. Bioconjug. Chem. 1993, 4, 372-379.

[4] Gottschalk, S.; Sparrow, J. T.; Hauer, J.; Mims, M. P.; Leland, F. E.; Woo, S. L. C.; Smith. L. C. A novel DNApeptide complex for efficient gene transfer and expression in mammalian cells. Gene Ther. 1996, 3, 448-457.

[5] Blessing, T.; Remy, J. S.; Behr J. P. Monomolecular collapse of plasmid DNA into stable virus-like particles. Proc. Natl. Acad. Sci. USA 1998, 95, 1427-1431.

[6] Kneuer, C.; Sameti, M.; Bakowsky, U.; Schiestel, T.; Schirra, H.; Schmidt, H.; Lehr, C. M. A nonviral DNA delivery system based on surface modified silicananoparticles can efficiently transfect cells in vitro. Bioconjug. Chem. 2000, 11, 926-932.

[7] lijima, S. Helical microtubules of graphitic carbon. Nature 1991, 354, 56-58.

[8] Cui, D.; Tian, F.; Kong, Y.; Titushikin, I.; Gao, H. Effects of single-walled carbon nanotubes on the polymerase chain reaction. Nanotechnology 2004, 15, 154-157.

[9] Mattson, M. P.; Haddon, R. C.; Rao, A. M. Molecular functionalization of carbon nanotubes and use as substrates for neuronal growth. J. Mol. Neurosci. 2000, 14, 175-182.

[10] Pantarotto, D.; Briand, J.; Prato, M.; Bianco, A. Translocation of bioactive peptides across cell membranes by carbon nanotubes. Chem. Commun. 2004, 16-17.

[11] Pantarotto, D.; Singh, R.; McCarthy, D.; Erhardt, M.; Briand, J.; Prato, M.; Kostarelos, K.; Bianco, A. Functionalized carbon nanotubes for plasmid DNA gene delivery. Angew. Chem. Int. Ed. 2004, 43, 5242-5246.

[12] Kam, N. W. S.; Jessop, T. C.; Wender, P. A; Dai, H. Nanotube molecular transporters: Internalization of carbon nanotube-protein conjugates into mammalian cells. J. Am. Chem. Soc. 2004, 126, 6850-6851.

[13] Kam, N. W. S.; Liu, Z.; Dai, H. Functionalization of carbon nanotubes via cleavable disulfide bonds for efficient intracellular delivery of siRNA and potent gene silencing. J. Am. Chem. Soc. 2005, 127, 12492-12493.

[14] Gao, L.; Nie, L.; Wang, T.; Qin, Y.; Guo, Z.; Yang, D.; 
Yan. X. Carbon nanotube delivery of the gfp gene into mammalian cells. ChemBioChem. 2006, 7, 239-242.

[15] Liu, Y.; Wu, D. -C.; Zhang, W. -D.; Jiang, X.; He, C. -B.; Chung, T. S.; Goh, S. H.; Leong, K. W. Polyethylenimine-grafted multiwalled carbon nanotubes for secure noncovalent immobilization and efficient delivery of DNA. Angew. Chem. Int. Ed. 2005, 44, 4782-4785.

[16] Singh, R.; Pantarotto, D.; McCarthy, D.; Chaloin, O.; Hoebeke, J.; Partidos, C. D.; Briand, J. -P.; Prato, M.; Bianco, A.; Kostarelos, K. Functionalized carbon nanotubes for plasmid DNA gene delivery. J. Am. Chem. Soc. 2005, 127, 4388-4396.

[17] Tans, S. C.; Verschueren, A. R. M.; Dekker, C. Roomtemperature transistor based on a single carbon nanotube. Nature 1998, 393, 49-52.

[18] Balasubramanian, K.; Burghard; M. Chemically functionalized carbon nanotubes. Small 2005, 1, 180-192.

[19] Richard, C.; Balavoine, F.; Schultz, P.; Ebbesen, T. W.; Mioskowski, C. Supramolecular self-assembly of lipid derivatives on carbon nanotubes. Science 2003, 300, 775-778.

[20] Richard, C.; Balavoine, F.; Schultz, P.; Moreau, N.; Mioskowski, C. Immobilization of histidine-tagged pro- teins on functionalized carbon nanotubes. J. Bionanosci. 2007, 1, 106-113.

[21] Scherman, D.; Bessodes, M.; Cameron, B.; Herscovici, J.; Hofland, H.; Pitard, B.; Soubrier, F.; Wils, P. Application of lipids and plasmid design for gene delivery to mammalian cells. J. Crouzet, Curr. Opin. Biotech. 1998, 9, 480-485.

[22] Byk, G.; Dubertret, C.; Escriou, V.; Frederic, M.; Jaslin, G.; Rangara, R.; Pitard, B.; Crouzet, J.; Wils, P.; Schwartz, B.; Scherman, D. Synthesis, activity, and structure-activity relationship studies of novel cationic lipids for DNA transfer. J. Med. Chem. 1998, 41, 224-235.

[23] Chen, R. J.; Zhang, Y.; Wang, D.; Dai, H. Noncovalent sidewall functionalization of single-walled carbon nanotubes for protein immobilization. J. Am. Chem. Soc. 2001, 123, 3838-3839.

[24] Escriou, V.; Ciolina, C.; Lacroix, F.; Byk, G.; Scherman, D.; Wils; P. Cationic lipid-mediated gene transfer: Effect of serum on cellular uptake and intracellular fate of lipopolyamine/DNA complexes. BBA, 1998, 1368, 276288.

[25] Lee, S. B.; Koepsel, R. R.; Russell, A. J. Surface dispersion and hardening of self-assembled diacetylene nanotubes. Nano Lett. 2005, 5, 2202-2206. 